\title{
Sistem Pendukung Keputusan Penentuan Minat Dalam Pemilihan Jurusan Peserta Didik Dengan Metode TOPSIS Pada SMAN 5 Cilegon
}

\author{
Achmad Syaefudin, Firda Safayanti \\ Program Studi Teknologi Informatika Sekolah Tinggi Ilmu Komputer Insan Unggul \\ Email :*1 asyaefudin1213@ gmail.com,.² firda.sy09@gmail.com
}

\begin{abstract}
Abstrak
SMAN 5 Cilegon merupakan sekolah menengah atas di Kota Cilegon yang setiap tahunnya rutin menyelenggaraan program pemilihan peminatan jurusan pada siswanya, terdapat 2 peminatan jurusan yaitu Matematika (MIA) dan Ilmu-ilmu Sosial (IIS). Pemilihan peminatan dilakukan atas dasar kebutuhan untuk melanjutkan keperguruan tinggi. Pemilihan peminatan berdasarkan kriteria yaitu prestasi belajar peserta didik yang diperoleh dari Nilai Ujian Nasional, Tes Penilaian Akademik, Angket Peminatan dan Wawancara. Masalah yang sering terjadi dalam proses pemilihan minat jurusan adalah kesulitan dalam mekanisme penilaian membutuhkan waktu yang lama dan juga hasil yang kurang akurat karena bisa saja terjadi kekeliruan, karena kurang tersedianya program (aplikasi) khusus dalam mendukung perhitungan tersebut. Oleh karena itu diperlukannya sistem pendukung keputusan untuk membantu guru Bimbingan Konseling (BK) dalam penentuan jurusan yang tepat di SMAN 5 Cilegon dengan metode Technique for Order Preference by Similarity to Ideal Solution (TOPSIS) yang menggunakan kriteria-kriteria yang telah ditentukan. Hasil akhir dari penelitian ini didapat bahwa sistem pendukung keputusan mampu mengatasi permasalahan dalam proses penentuan minat jurusan pada SMAN 5 Cilegon.
\end{abstract}

Kata kunci : sistem pendukung keputusan, penentuan peminatan jurusan, kriteria, TOSIS

\section{Abstract}

SMAN 5 Cilegon is one of the public high school in Cilegon, the majoring for students are regularly conducts, there are two major options namely Math and Natural Science (MIA) and the Social Sciences (IIS). The majoring is performed as a requirement to continue to the University level. Majoring based on criteria of students' learning achievement gained from National Examination scores, Academic Valuation Test, Students' Preferences Questionnaire and Interview. During the process of determining the major, the school often has to deal with several constraints such as the assessment takes a long time and the results are less accurate due to the lack of availability of programs (applications) that supports. Therefore, it needs an ideal Decision Support System for helping the counseling teacher (BK) carry out the process using Technique for Order Preference by Similarity to Ideal Solution (TOPSIS) that use predefined criteria. The result of the research obtained that the decision support system was success to cope with the problems in the process of majoring in SMAN 5 Cilegon.

Keyword : Topsis,Decesion Suport System,Academic Valuation Test 


\section{PENDAHULUAN}

Pemilihan peminatan dilakukan atas dasar kebutuhan untuk melanjutkan keperguruan tinggi. Namun masih ada SMA yang peminatannya masih 2 yaitu MIA dan IIS. Peminatan MIA dan IIS ini dilakukan pada SMAN 5 Cilegon. Dalam pemilihan peminatan ini, siswa dapat menentukan pilihan minatnya sesuai dengan bakat dan cita-citanya dimasa depan. Pemilihan peminatan berdasarkan kriteria yaitu prestasi belajar peserta didik yang diperoleh dari Nilai Ujian Nasional, Tes Penilaian Akademik, Angket Peminatan dan Wawancara. SMAN 5 Cilegon merupakan salah satu Sekolah Menengah Atas yang setiap tahunnya rutin melakukan pemilihan peminatan jurusan pada siswanya. Proses peminatan jurusan dilakukan oleh guru Bimbingan dan Konseling/BK dalam mengelola minat siswa agar dapat menentukan pilihan yang sesuai dengan potensi dan minatnya.

\section{Rumusan Masalah}

Masalah yang sering terjadi dalam proses pemilihan minat jurusan adalah kesulitan dalam mekanisme penilaian membutuhkan waktu yang lama dan juga hasil yang kurang akurat karena bisa saja terjadi kekeliruan, karena kurang tersedianya program (aplikasi) khusus dalam mendukung perhitungan tersebut. Oleh karena itu diperlukannya sistem pendukung keputusan untuk membantu guru Bimbingan Konseling (BK) dalam penentuan jurusan yang tepat di SMAN 5 Cilegon. Sistem Pendukung Keputusan (SPK) adalah salah satu cara mengorganisir informasi yang dimaksudkan untuk digunakan dalam membuat keputusan. Pembuatan SPK ini diharapkan akan menyelesaikan permasalahan yang dihadapi dan sistem yang dibangun nantinya menggunakan kriteria-kriteria yang relevan sehingga hasil akhirnya nanti yang terpilih merupakan pilihan yang paling tepat untuk siswa SMAN 5 Cilegon

TOPSIS (Technique For Order Preference By Similarity To Ideal Solution) adalah salah satu metode pengambilan keputusan multikriteria yang memilki konsep dimana alternatif yang terpilih merupakan alternatif terbaik yang memiliki jarak terpendek dari solusi ideal positif dan jarak terpanjang dari solusi ideal negatif.Metode ini banyak digunakan untuk menyelesaikan pengambilan keputusan secara praktis. Hal ini disebabkan konsepnya yang sederhana dan mudah dipahami, komputasinya efisien dan memiliki kemampuan mengukur kinerja relatif dari alternatif - alternatif keputusan dalam bentuk atematis yang sederhana.

Adapun tahapan - tahapan dalam metode TOPSIS yaitu:

a. membuat matriks keputusan yang ternormalisasi

b. membuat matriks keputusan yang ternormalisasi terbobot

c. menentukan matriks solusi ideal positif dan matriks solusi ideal negatif

d. menentukan jarak antara nilai setiap alternatif dangan matriks solusi ideal positif dan matriks solusi ideal negatif

e. menentukan nilai preferensi untuk setiap alternative

Langkah - langkah untuk menyelesaikan permasalahan menggunakan metode TOPSIS:

a. Membuat matriks keputusan yang ternormalisasi(1).

Metode TOPSIS membutuhkan rating kinerja setiap alternatif Ai pada setiap kriteria Ci yang ternormalisasi.

$$
r i j=\frac{X_{i j}}{\sqrt{\sum_{i=1}^{m} x_{i j}^{2}}}
$$

Dengan $i=1,2, \ldots \ldots, \mathrm{m} ;$ dan $j=1,2, \ldots . ., \mathrm{n}$.

$r i j=$ matriks keputusan ternormalisasi.

$x i j=$ bobot kriteria ke j pada alternatif ke $\mathrm{i}$.

$\mathrm{i}=$ alternatif ke $\mathrm{i}$.

$\mathrm{j}=$ kriteria ke $\mathrm{j}$.

b. Membuat matriks keputusan yang ternormalisasi terbobot(2). 


$$
\mathrm{Y}=\left(\begin{array}{lll}
y_{11} & y_{22} & y_{1 j} \\
y_{22} & y_{23} & y_{2 j} \\
y_{i 1} & y_{i 2} & y_{i j}
\end{array}\right) \text { untuk } y i j=w j . r i j
$$

Keterangan:

$W i j$ adalah bobot kriteria ke- $j$

$Y i j$ adalah elemen dari matriks keputusan yang ternormalisasi.

c. Menentukan matriks solusi ideal positif dan matriks solusi ideal negatif(3),(4).

Dimana :

$$
\begin{aligned}
& A^{+}=\left(y_{1}+y_{2}+y_{3}\right) \\
& A^{-}=\left(y_{1}+y_{2}+y_{3}\right)
\end{aligned}
$$

$Y_{j}^{+}=\max$ yij dan $\mathrm{j}$ adalah atribut keuntungan min yij, jika $\mathrm{j}$ adalah atribut biaya

$Y_{j}^{-}=\max$ yij dan $\mathrm{j}$ adalah atribut keuntungan min yij, jika $\mathrm{j}$ adalah atribut biaya

d. Menentukan jarak antara nilai setiap alternatif dengan matriks solusi ideal positif (D+) dan (D) matriks solusi ideal negatif(5),(6).

$$
\begin{aligned}
& D_{i}^{+}=\sqrt{ } \sum_{i=1}^{n}\left(Y_{i}^{+}-Y_{i j}^{-}\right)^{2} ; \mathrm{i}=1,2, \ldots \mathrm{m} \\
& D_{i}^{-}=\sqrt{ } \sum_{i=1}^{n}\left(y_{i j}-Y_{i}^{-}\right)^{2} ; \mathrm{i}=1,2, \ldots \mathrm{m}
\end{aligned}
$$

Keterangan :

$Y_{j}^{+}$adalah elemen dari matriks solusi ideal positif.

$Y_{j}^{-}$adalah elemen dari matriks solusi ideal negatif.

e. Menentukan nilai preferensi untuk setiap alternatif. Nilai preferensi merupakan kedekatan suatu alternatif terhadap solusi ideal (7).

$$
V_{i}=\frac{D_{i}^{-}}{D_{i}^{-}+D_{i}^{+}}
$$

Dimana:

Nilai Vi yang lebih besar menunjukkan prioritas alternatif.

\section{METODE PENELITIAN}

Metode pengembangan Prototyping yang berupa model fisik kerja sistem dan berfungsi sebagai versi awal dari sistem. Dengan metode prototyping ini akan dihasilkan prototype sistem sebagai perantara pengembang dan pengguna agar dapat berinteraksi dalam proses kegiatan pengembangan sistem informasi. Agar proses pembuatan prototype ini berhasil dengan baik adalah dengan mendefinisikan aturan-aturan pada tahap awal, yaitu pengembang dan penguna harus satu pemahaman bahwa prototype dibangun untuk mendefinisikan kebutuhan awal.

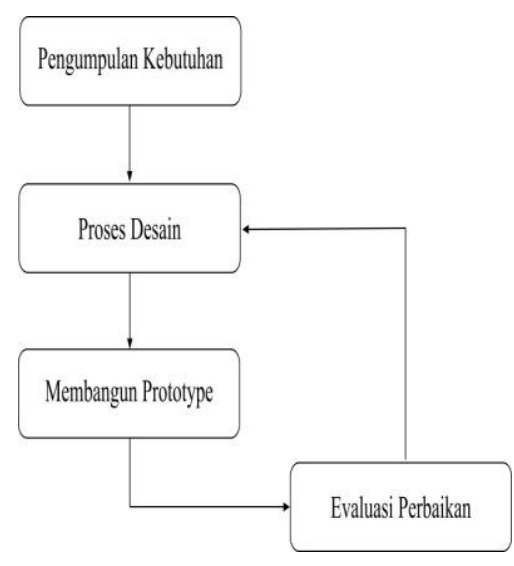

Gambar 1. Tahapan Penelitian 
Flowchat Penelitian

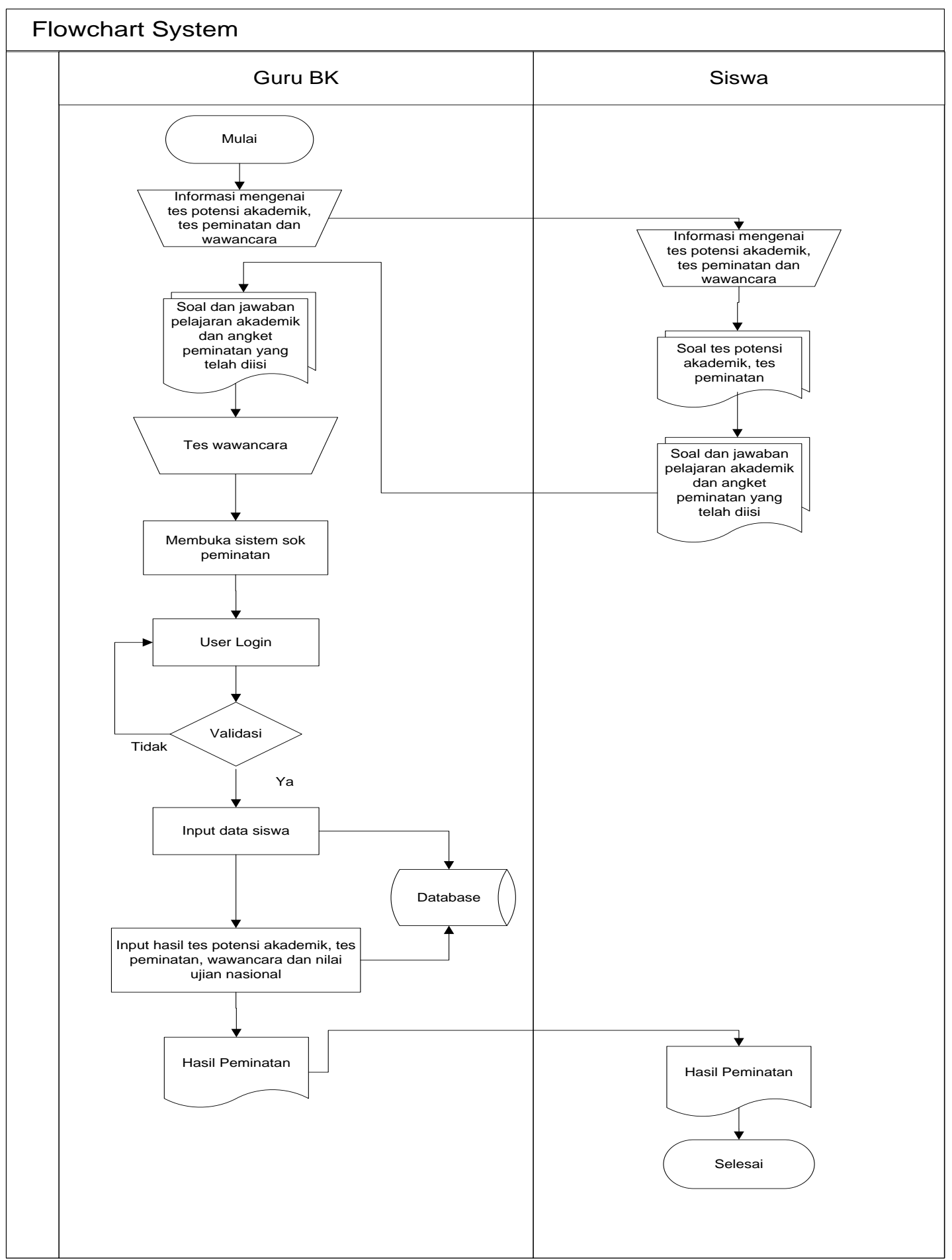

Gambar 2. Flowchart Sistem 
Model ERD

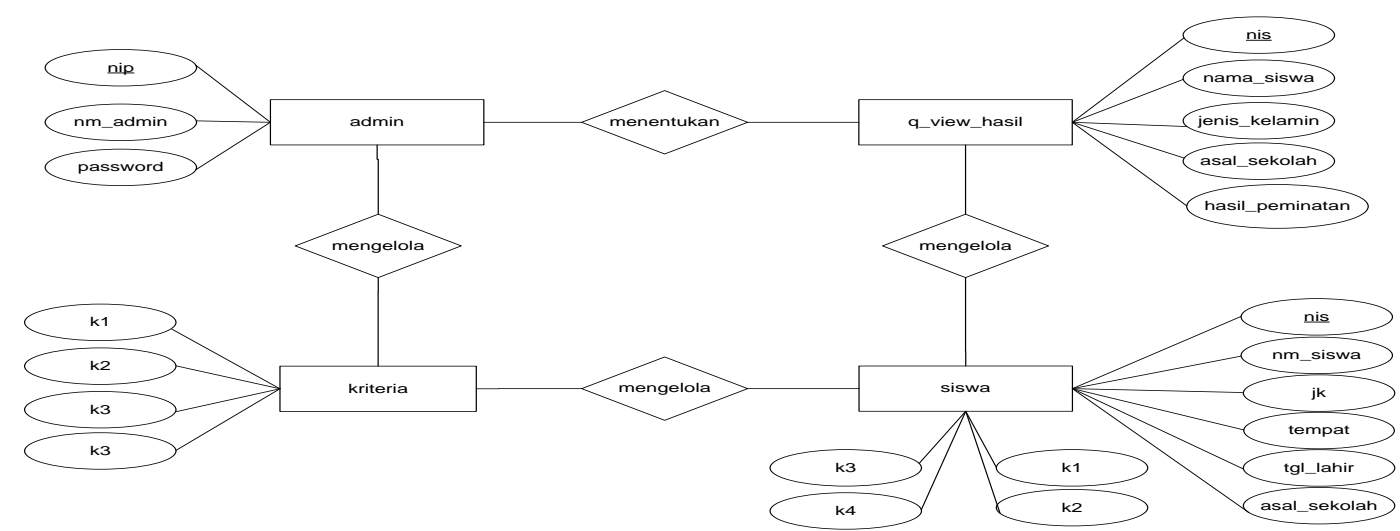

Gambar 3. Entity Relationship Diagram

Pemodelan Sistem UML Use Case Diagram Sistem Penunjang Keputusan

Berikut adalah use case diagram untuk menunjukan fungsionalitas suatu sistem atau kelas dan bagaimana sistem dapat berinteraksi dengan pengguna atau user. Berikut use case diagram sistem.

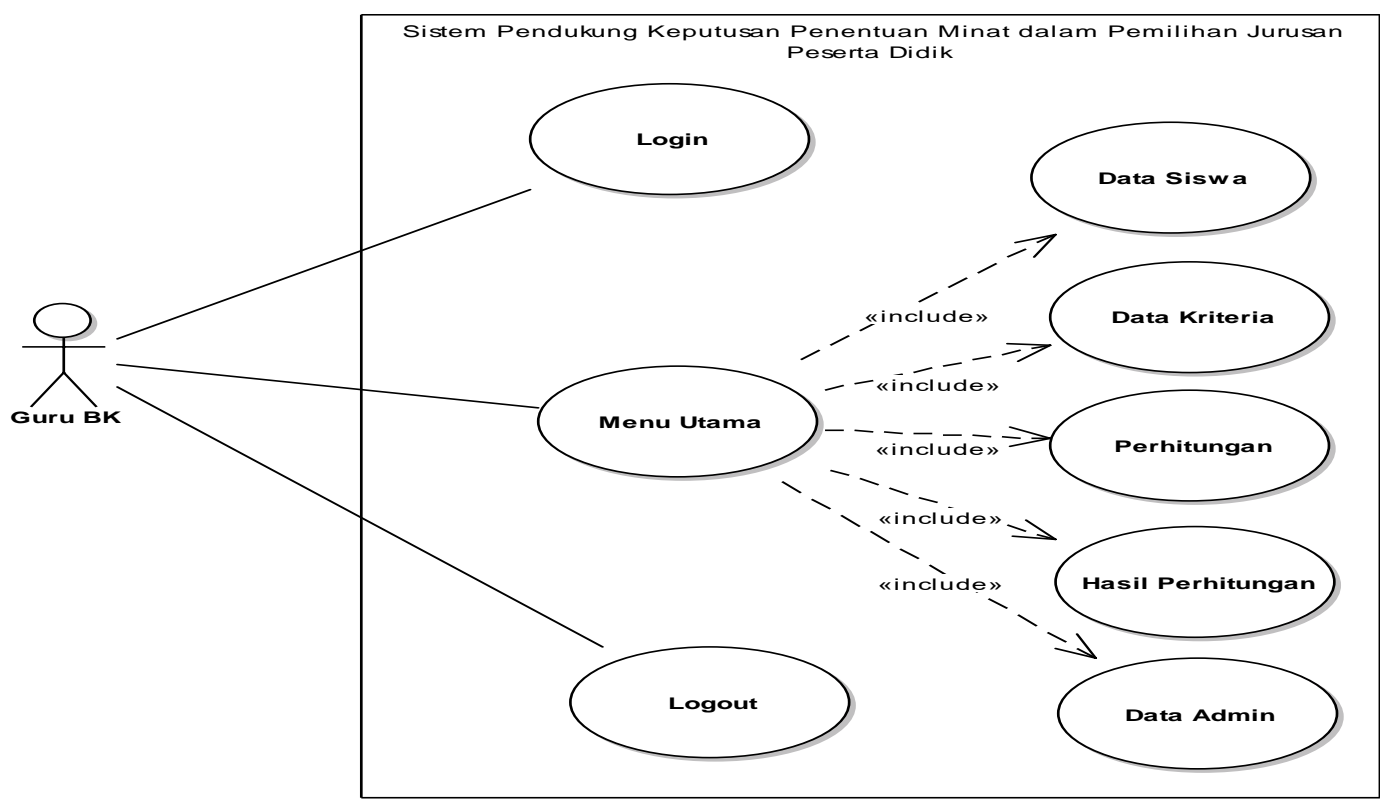

Gambar 4 Use Case Diagram Sistem Pendukung Keputusan 
Activity Perhitungan

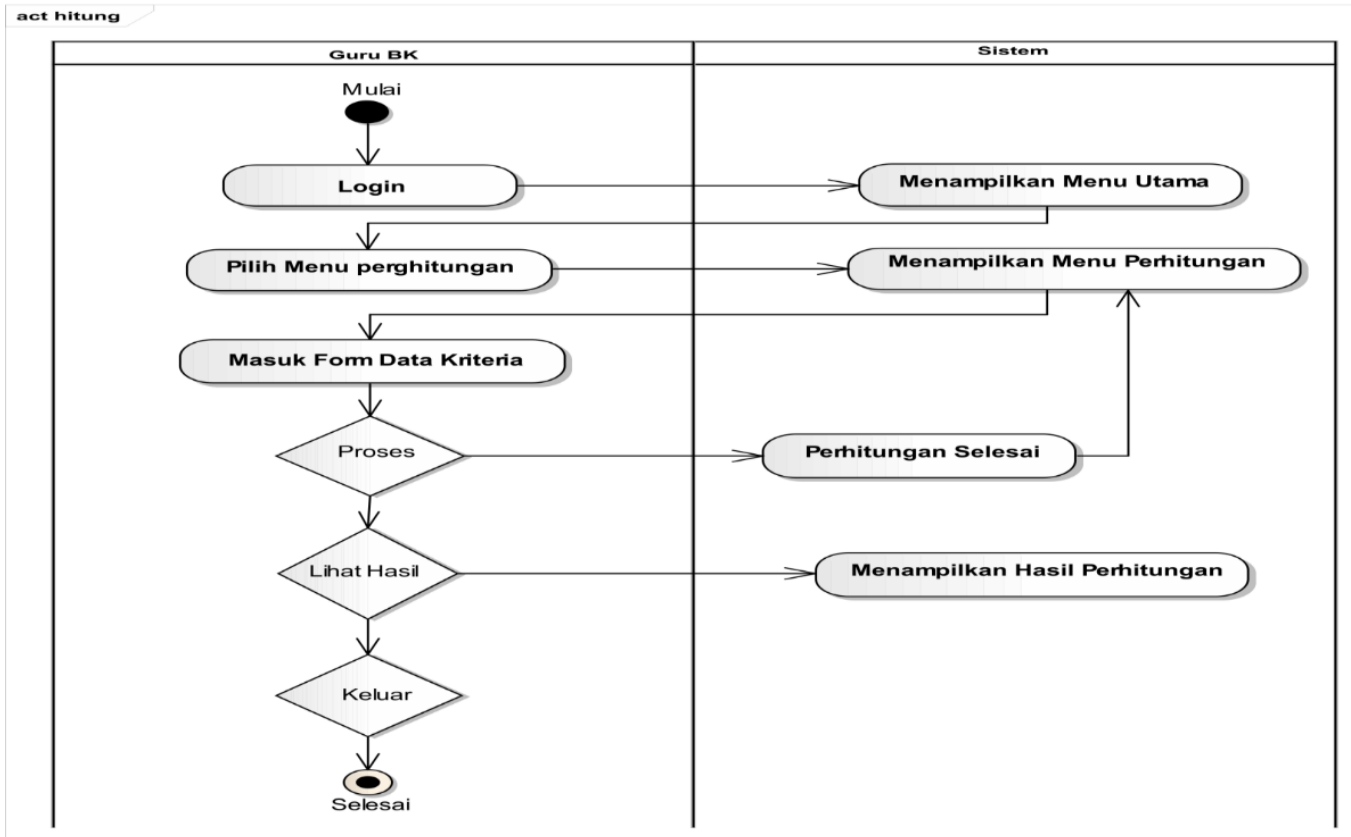

Gambar 5. Diagram Activity Perhitungan

\section{HASIL DAN PEMBAHASAN}

Menentukan nilai relatif terhadap masing-masing alternatif Sampel perhitungan ntuk masing-masing pengesub dapat dilihat pada Table 4.1.

Table 4.1 Nilai Alternatif terhadap masing-masing kriteria

\begin{tabular}{|l|l|l|l|l|l|}
\hline NO & Nama Siswa & $\begin{array}{l}\text { Rata-rata } \\
\text { UN }\end{array}$ & TAP & Angket & Wawancara \\
\hline 1 & Adam Dzaky & 55 & 43 & 100 & 50 \\
\hline 2 & Adelia Putri & 48,75 & 41 & 100 & 100 \\
\hline 3 & Evita Sari & 28,75 & 37 & 50 & 50 \\
\hline 4 & Fajar Layyinul Qulub & 33,75 & 23 & 100 & 50 \\
\hline 5 & Fulaiyah & 56,25 & 25 & 50 & 50 \\
\hline 6 & Qori Andal Cahayani & 42,5 & 23 & 100 & 50 \\
\hline 7 & Lexy Refaldy & 73,5 & 24 & 100 & 100 \\
\hline 8 & Ahmad Farid & 71,25 & 32 & 100 & 100 \\
\hline 9 & Brantas Satria Adikara & 33,75 & 27 & 100 & 50 \\
\hline 10 & Chyntia Damayanti & 47,5 & 25 & 50 & 50 \\
\hline 11 & Dava Aditya Karindra & 38,75 & 26 & 100 & 50 \\
\hline 12 & Deah Anajwa & 25 & 34 & 50 & 50 \\
\hline 13 & Elsa Febriyana & 30 & 35 & 50 & 50 \\
\hline 14 & Faisal Tamimi & 33,75 & 32 & 50 & 50 \\
\hline 15 & Hani Wijaya & 48,75 & 26 & 100 & 100 \\
\hline 16 & Galih Rakasiwi & 37,5 & 30 & 100 & 100 \\
\hline 17 & Indriyani & 47,5 & 33 & 100 & 100 \\
\hline
\end{tabular}




\begin{tabular}{|l|l|l|l|l|l|}
18 & Wahyu Wanda Asmara & 42,5 & 33 & 50 & 50 \\
\hline 19 & Zidane Ramadhan & 40 & 24 & 50 & 50 \\
\hline 20 & Yuni Apriliani & 50 & 29 & 100 & 100 \\
\hline
\end{tabular}

\section{Menentukan matriks keputusan ternormalisasi}

a. Untuk kriteria rata-rata nilai $\mathrm{UN}\left(C_{1}\right)$

$$
\begin{aligned}
& C_{1}=\sqrt{\begin{array}{c}
(55)^{2}+(48,75)^{2}+(28,75)^{2}+(33,75)^{2}+(56,25)^{2}+(42,5)^{2}+ \\
(73,5)^{2}+(71,5)^{2}+(33,75)^{2}+(47,5)^{2}+(38,75)^{2}+(25)^{2}+ \\
(30)^{2}+(33,75)^{2}+(48,75)^{2}+(37,5)^{2}+(47,5)^{2}+(42,5)^{2}+ \\
(40)^{2}+(50)^{2}
\end{array}} \\
& =205,7245
\end{aligned}
$$

$$
\begin{array}{lc}
R_{11}=X_{11} / C_{1}=55 / 205,7245 & =0,2673 \\
R_{21}=X_{21} / C_{1}=48,75 / 205,7245 & =0,2369 \\
R_{31}=X_{31} / C_{1}=28,75 / 205,7245 & =0,1397 \\
R_{41}=X_{41} / C_{1}=33,75 / 205,7245 & =0,1640 \\
R_{51}=X_{51} / C_{1}=56,25 / 205,7245 & =0,2734 \\
R_{61}=X_{61} / C_{1}=42,5 / 205,7245 & =0,2065 \\
R_{71}=X_{71} / C_{1}=73,5 / 205,7245 & =0,3572 \\
R_{81}=X_{81} / C_{1}=71,5 / 205,7245 & =0,3463 \\
R_{91}=X_{91} / C_{1}=33,75 / 205,7245 & =0,1640 \\
R_{101}=X_{101} / C_{1}=47,5 / 205,7245 & =0,2308 \\
R_{111}=X_{111} / C_{1}=38,75 / 205,7245 & =0,1883 \\
R_{121}=X_{121} / C_{1}=25 / 205,7245 & =0,1215 \\
R_{131}=X_{131} / C_{1}=30 / 205,7245 & =0,1458 \\
R_{141}=X_{141} / C_{1}=33,75 / 205,7245 & =0,1640 \\
R_{151}=X_{151} / C_{1}=48,75 / 205,7245 & =0,2369 \\
R_{161}=X_{161} / C_{1}=37,5 / 205,7245 & =0,1822 \\
R_{171}=X_{171} / C_{1}=47,5 / 205,7245 & =0,2308 \\
R_{181}=X_{181} / C_{1}=42,5 / 205,7245 & =0,2065 \\
R_{191}=X_{191} / C_{1}=40 / 205,7245 & =0,1944 \\
R_{201}=X_{201} / C_{1}=50 / 205,7245 & =0,2430
\end{array}
$$

b. Untuk kriteria TAP $\left(C_{2}\right)$

$$
\begin{aligned}
& C_{2}=\sqrt{\begin{array}{c}
(43)^{2}+(41)^{2}+(37)^{2}+(23)^{2}+(25)^{2}+(23)^{2}+(24)^{2}+(32)^{2}+ \\
(27)^{2}+(25)^{2}+(26)^{2}+(34)^{2}+(35)^{2}+(32)^{2}+(26)^{2}+(30)^{2}+ \\
(33)^{2}+(33)^{2}+(24)^{2}+(29)^{2}+++++++++++++++
\end{array}} \\
& =137,0693
\end{aligned}
$$

$$
\begin{array}{ll}
R_{11}=X_{11} / C_{2}=43 / 137,0693 & =0,2673 \\
R_{21}=X_{21} / C_{2}=41 / 137,0693 & =0,2369 \\
R_{31}=X_{31} / C_{2}=37 / 137,0693 & =0,1397 \\
R_{41}=X_{41} / C_{2}=23 / 137,0693 & =0,1640 \\
R_{51}=X_{51} / C_{2}=25 / 137,0693 & =0,2734 \\
R_{61}=X_{61} / C_{2}=23 / 137,0693 & =0,2065 \\
R_{71}=X_{71} / C_{2}=24 / 137,0693 & =0,3572
\end{array}
$$




$$
\begin{array}{ll}
R_{81}=X_{81} / C_{2}=32 / 137,0693=0,3463 & \\
R_{91}=X_{91} / C_{2}=27 / 137,0693=0,1640 & \\
R_{101}=X_{101} / C_{2}=25 / 137,0693 & =0,2308 \\
R_{111}=X_{111} / C_{2}=26 / 137,0693 & =0,1883 \\
R_{121}=X_{121} / C_{2}=34 / 137,0693 & =0,1215 \\
R_{131}=X_{131} / C_{2}=35 / 137,0693 & =0,1458 \\
R_{141}=X_{141} / C_{2}=32 / 137,0693 & =0,1640 \\
R_{151}=X_{151} / C_{2}=26 / 137,0693 & =0,2369 \\
R_{161}=X_{161} / C_{2}=30 / 137,0693 & =0,1822 \\
R_{171}=X_{171} / C_{2}=33 / 137,0693 & =0,2308 \\
R_{181}=X_{181} / C_{2}=33 / 137,0693 & =0,2065 \\
R_{191}=X_{191} / C_{2}=24 / 137,0693 & =0,1944 \\
R_{201}=X_{201} / C_{2}=29 / 137,0693 & =0,2430
\end{array}
$$

Dan seterusnya, sehingga didapat Tabel 4.2.

Tabel 4.2 Matriks Ternormalisasi

\begin{tabular}{|l|l|l|l|}
\hline 0,2673 & 0,3137 & 0,2673 & 0,1562 \\
\hline 0,2370 & 0,2991 & 0,2673 & 0,3123 \\
\hline 0,1398 & 0,2699 & 0,1336 & 0,1562 \\
\hline 0,1641 & 0,1678 & 0,2673 & 0,1562 \\
\hline 0,2734 & 0,1824 & 0,1336 & 0,1562 \\
\hline 0,2066 & 0,1678 & 0,2673 & 0,1562 \\
\hline 0,3573 & 0,1751 & 0,2673 & 0,3123 \\
\hline 0,3463 & 0,2335 & 0,2673 & 0,3123 \\
\hline 0,1641 & 0,1970 & 0,2673 & 0,1562 \\
\hline 0,2309 & 0,1824 & 0,1336 & 0,1562 \\
\hline 0,1884 & 0,1897 & 0,2673 & 0,1562 \\
\hline 0,1215 & 0,2480 & 0,1336 & 0,1562 \\
\hline 0,1458 & 0,2553 & 0,1336 & 0,1562 \\
\hline 0,1641 & 0,2335 & 0,1336 & 0,1562 \\
\hline 0,2370 & 0,1897 & 0,2673 & 0,3123 \\
\hline 0,1823 & 0,2189 & 0,2673 & 0,3123 \\
\hline 0,2309 & 0,2408 & 0,2673 & 0,3123 \\
\hline 0,2066 & 0,2408 & 0,1336 & 0,1562 \\
\hline 0,1944 & 0,1751 & 0,1336 & 0,1562 \\
\hline 0,2430 & 0,2116 & 0,2673 & 0,3123 \\
\hline & & &
\end{tabular}

1. Menentukan matriks keputusan normalisasi terbobot

Sebelum menghitung matriks keputusan normalisasi bobot, tentukan terlebih dahulu bobot dari masing masing kriteria pada Tabel 1.3. 
Tabel 3.3 Bobot Kriteria

\begin{tabular}{|c|l|c|}
\hline No & \multicolumn{1}{|c|}{ Kriteria } & Bobot $(\mathrm{W})$ \\
\hline 1. & Rata-rata nilai UN & 25 \\
\hline 2. & Tes Penilaian Akademik & 25 \\
\hline 3. & Angket & 25 \\
\hline 4. & Wawancara & 25 \\
\hline
\end{tabular}

Setelah menentukan bobot dari masing-masing kriteria, maka berdasarkan langkah 1 dan persamaan 2, kita dapat menghitung matriks ternormalisasi terbobot yaitu :

a. Untuk kriteria rata-rata nilai $\mathrm{UN}$

$$
\begin{array}{lr}
Y_{11}=W_{11} * R_{11}=25 * 0,2673 & =6,6836 \\
Y_{21}=W_{11} * R_{21}=25 * 0,2369 & =5,9241 \\
Y_{31}=W_{11} * R_{31}=25 * 0,1397 & =3,4937 \\
Y_{41}=X_{11} * R_{41}=25 * 0,1640 & =4,1013 \\
Y_{51}=X_{11} * R_{51}=25 * 0,2734 & =6,8355 \\
Y_{61}=X_{11} * R_{61}=25 * 0,2065 & =5,1646 \\
Y_{71}=X_{11} * R_{71}=25 * 0,3572 & =8,9318 \\
Y_{81}=X_{11} * R_{81}=25 * 0,3463 & =8,6584 \\
Y_{91}=X_{11} * R_{91}=25 * 0,1649 & =4,1013 \\
Y_{101}=X_{11} * R_{101}=25 * 0,2308 & =5,7722
\end{array}
$$

Dan seterusnya, sehingga didapat Tabel 4.4

Tabel 4.4 Matriks Normalisasi Bobot

\begin{tabular}{|l|l|l|l|}
\hline 6,6837 & 7,8427 & 6,6815 & 3,9043 \\
\hline 5,9242 & 7,4780 & 6,6815 & 7,8087 \\
\hline 3,4938 & 6,7484 & 3,3408 & 3,9043 \\
\hline 4,1014 & 4,1950 & 6,6815 & 3,9043 \\
\hline 6,8356 & 4,5597 & 3,3408 & 3,9043 \\
\hline
\end{tabular}




\begin{tabular}{|l|l|l|l|}
5,1647 & 4,1950 & 6,6815 & 3,9043 \\
\hline 8,9318 & 4,3773 & 6,6815 & 7,8087 \\
\hline 8,6584 & 5,8365 & 6,6815 & 7,8087 \\
\hline 4,1014 & 4,9245 & 6,6815 & 3,9043 \\
\hline 5,7723 & 4,5597 & 3,3408 & 3,9043 \\
\hline 4,7090 & 4,7421 & 6,6815 & 3,9043 \\
\hline 3,0380 & 6,2012 & 3,3408 & 3,9043 \\
\hline 3,6457 & 6,3836 & 3,3408 & 3,9043 \\
\hline 4,1014 & 5,8365 & 3,3408 & 3,9043 \\
\hline 5,9242 & 4,7421 & 6,6815 & 7,8087 \\
\hline 4,5571 & 5,4717 & 6,6815 & 7,8087 \\
\hline 5,7723 & 6,0189 & 6,6815 & 7,8087 \\
\hline 5,1647 & 6,0189 & 3,3408 & 3,9043 \\
\hline 4,8609 & 4,3773 & 3,3408 & 3,9043 \\
\hline 6,0761 & 5,2893 & 6,6815 & 7,8087 \\
\hline & & & \\
\hline
\end{tabular}

\section{Menentukan matriks solusi ideal positif dan matriks solusi negatif}

Langkah selanjutnya yaitu menentukan matriks solusi ideal positif dan matriks solusi ideal negatif berdasarkan persamaan 3 dan 4 .

$$
\begin{aligned}
& A^{+}=\left(y_{1}^{+}, y_{2}^{+}, y_{3}^{+}, \ldots, y_{n}^{+}\right) \\
& A^{-}=\left(y_{1}^{-}, y_{2}^{-}, y_{3}^{-}, \ldots, y_{n}^{-}\right)
\end{aligned}
$$

Solusi ideal positif dihitung sebagai berikut :

$$
\begin{aligned}
& y_{1}^{+}=\max \{6,683696498 ; 5,924185532 ; 3,493750442 \ldots \ldots\}=8,931848956 \\
& y_{2}^{+}=\max \{7,842746697 ; 7,477967781 ; 6,748409948 \ldots \ldots\}=7,842746697 \\
& \text { dan seterusnya } \\
& A^{+}=\{8,931848956 ; 7,842746697 ; 6,681531048 ; 7,808688094\}
\end{aligned}
$$

Solusi ideal negatif dihitung sebagai berikut :

$$
\begin{aligned}
& y_{1}^{-}=\min \{6,683696498 ; 5,924185532 ; 3,493750442 \ldots \ldots\}=3,038043863 \\
& y_{2}^{-}=\min \{7,842746697 ; 7,477967781 ; 6,748409948 \ldots \ldots\}=4,194957536 \\
& \text { dan seterusnya } \\
& A^{-}=\{3,038043863 ; 4,194957536 ; 3,340765524 ; 3,904344047\}
\end{aligned}
$$

Tabel 4.5 Matriks Solusi Ideal Positif dan Matriks Solusi Ideal Negatif

\begin{tabular}{|c|c|c|c|c|}
\hline Alternatif & C1 & C2 & C3 & C4 \\
\hline A+ & 8,9318 & 7,8427 & 6,6815 & 7,8086 \\
\hline A- & 3,0380 & 4,1949 & 3,3407 & 3,9043 \\
\hline
\end{tabular}

Menentukan jarak antara nilai setiap alternatif dengan matriks solusi ideal positif dan matriks solusi ideal negative. Selanjutnya untuk mencari jarak antara alternatif dengan matriks solusi ideal positif dapat menggunakan persamaan berikut ini :

$$
D_{i}^{+}=\sqrt{ } \sum_{i=1}^{n}\left(Y_{i}^{+}-Y_{i j}^{-}\right)^{2} ; \mathrm{i}=1,2, \ldots \mathrm{m}
$$

Jarak antara alternatif A, dengan solusi ideal negatif dirumuskan sebagai :

$$
D_{i}^{-}=\sqrt{ } \sum_{i=1}^{n}\left(y_{i j}-Y_{i}^{-}\right)^{2} ; \mathrm{i}=1,2, \ldots \mathrm{m}
$$


Membuat jarak antara nilai terbobot setiap alternatif terhadap solusi ideal positif Nilai jarak solusi ideal positif untuk rata-rata nilai UN.

$$
\begin{aligned}
D_{1}^{+} & =\sqrt{\begin{array}{c}
(6,6836-8,9318)^{2}+(7,8427-7,8427)^{2}+ \\
(6,6815-6,6815)^{2}+(3,9043-7,8086)^{2}
\end{array}} \\
& =4,505340377
\end{aligned}
$$

Dan seterusnya.

$$
\begin{aligned}
D_{1}^{-} & =\sqrt{\begin{array}{c}
(6,6836-3,0380)^{2}+(7,8427-4,1949)^{2}+ \\
(6,6815-3,3407)^{2}+(3,9043-3,9043)^{2}
\end{array}} \\
& =5,471555028
\end{aligned}
$$

Demikian seterusnya, terakhir diperoleh jarak solusi ideal positif dan negatif.

Tabel 4.6 Jarak Solusi Ideal Positif Dan Negatif

\begin{tabular}{|c|c|}
\hline 4,505340377 & 5,471555028 \\
\hline 3,029703439 & 6,139433033 \\
\hline 7,561422161 & 2,593797932 \\
\hline 7,203047921 & 2,114569711 \\
\hline 6,448025913 & 3,815034251 \\
\hline 6,537726752 & 2,804161849 \\
\hline 3,465399703 & 7,304441961 \\
\hline 2,024829943 & 7,271030963 \\
\hline 6,862478246 & 2,23688616 \\
\hline 6,867723632 & 2,758465003 \\
\hline 6,533794869 & 2,536167617 \\
\hline 7,989749325 & 2,006284039 \\
\hline 7,515151814 & 2,271448898 \\
\hline 7,332354568 & 1,955806382 \\
\hline 4,319709312 & 5,216691953 \\
\hline 4,976009169 & 4,745748139 \\
\hline 3,648211388 & 5,42100774 \\
\hline 6,627428691 & 2,801633379 \\
\hline 7,415286914 & 1,83192841 \\
\hline 3,830860404 & 5,386274352 \\
\hline
\end{tabular}

2. Langkah terakhir dalam proses perhitungan TOPSIS adalah mencari nilai preferensi untuk setiap alternatif.

$$
\begin{aligned}
V_{1} & =\frac{5,471555028}{5,471555028-4,505340377} \\
& =0,548422611
\end{aligned}
$$


Dan seterusnya, sehingga didapat Tabel 4.7.

Tabel 4.7 Nilai Preferensi

\begin{tabular}{|l|c|c|}
\hline Adam Dzaky & 0,5484 & MIA \\
\hline Adelia Putri & 0,6696 & MIA \\
\hline Evita Sari & 0,2554 & IIS \\
\hline Fulaiyah & 0,2269 & IIS \\
\hline Qori Andal Cahayani & 0,3717 & IIS \\
\hline Lexy Refaldy & 0,3002 & IIS \\
\hline Ahmad Farid & 0,6782 & MIA \\
\hline Brantas Satria Adikara & 0,7822 & MIA \\
\hline Chyntia Damayanti & 0,2458 & IIS \\
\hline Dava Aditya Karindra & 0,2866 & IIS \\
\hline Deah Anajwa & 0,2796 & IIS \\
\hline Elsa Febriyana & 0,2007 & IIS \\
\hline Faisal Tamimi & 0,2321 & IIS \\
\hline Hani Wijaya & 0,2106 & IIS \\
\hline Galih Rakasiwi & 0,5470 & MIA \\
\hline Indriyani & 0,4882 & MIA \\
\hline Wahyu Wanda Asmara & 0,5977 & MIA \\
\hline Zidane Ramadhan & 0,2971 & IIS \\
\hline Yuni Apriliani & 0,1981 & IIS \\
\hline Zalfa Faross Nurafifah & 0,5844 & MIA \\
\hline
\end{tabular}

\section{KESIMPULAN}

Berdasarkan uraian dan pembahasan beberapa bab sebelumnya, maka dapat diambil kesimpulannya bahwa :

1. Sistem pendukung keputusan penentuan minat dalam pemilihan jurusan menggunakan metode Technique For Order Preference By Similarity To Ideal Solution dibuat menggunakan program berupa Microsoft Visual Studio.NET 2010 Bahasa Pemograman Visual Basic dan databasenya menggunakan Microsoft Access. Sistem pendukung keputusan dalam pemilihan Penentuan minat dalam pemilihan jurusan memiliki form login, menu utama, form siswa, form kriteria, form perhitungan, form hasil perhitungan dan form admin. Sehingga dapat mempermudah dalam penginputan data siswa dan mengelola nilai dalam proses menentukan minat dalam pemilihan jurusan dengan menggunakan kriteria yang telah ditetapkan seperti : nilai ujian nasional, penilaian akademik, hasil angket peminatan dan hasil wawancara.

2. Sistem pendukung keputusan penentuan minat dalam pemilihan jurusan menggunakan metode Technique For Order Preference By Similarity To Ideal Solution menggunakan 4 kriteria, yaitu Nilai Ujian Nasional, Test Potensi Akademik, Angket Peminatan dan Wawancara. Pada tugas akhir ini kriteria yang digunakan oleh Guru BK sama dengan kriteria yang digunakan oleh sistem. Hasil peminatan jurusan yang telah dilakukan oleh sistem hampir mendekati saran peminatan jurusan yang diberikan oleh Guru BK. Berdasarkan data siswa yang digunakan dalam penelitian berjumlah 20 siswa yang diperoleh 17 siswa yang hasilnya sama dengan saran diberikan oleh Guru BK. 


\section{SARAN}

Melihat hasil yang dicapai pada penelitian ini, ada beberapa hal yang penulis menyarankan untuk pengembangan selanjutnya dan memperhatikan hal-hal seperti :

1. Diharapkan pengembangan sistem yang baru sesuai dengan tampilan yang lebih baik dan menarik.

2. Perlu adanya pelatihan sumber daya manusia untuk mengoprasikan sistem agar tidak terjadi kesalahan.

3. Perlu adanya backup data secara bersekala dan perawatan (maintenance) harus dilakukan untuk menunjang sistem yang baik dan sesuai harapan.

\section{DAFTAR PUSTAKA}

[1]. Dahlan, Muhammad. 2017. Sistem Pendukung Keputusan Penentuan Jurusan Siswa Man Bangil Menggunakan Metode TOPSIS. Universitas Islam Negeri Maulana Malik Ibrahim : Tugas Akhir

[2]. Darmadi. 2017. Pengembangan Model Metode Pembelajaran dalam Dinamik Belajar Siswa. Yogyakarta : Deepublish

[3]. Fakhrur R, Muhammad. 2015. Sistem Pendukung Keputusan dalam Memilih Jurusan SMA Menggunakan Model Yager. Fakultas Matematika dan Ilmu Pengetahuan Alam : Tugas Akhir

[4]. Hidayatullah, Priyanto. 2015. Visual Basic .NET Membuat Aplikasi Database dan Pemograman Kreatif. Bandung : Informatika Bandung

[5]. Kusumo, Ari S. 2016. Administrasi SQL Server 2014. Jakarta : PT. Alex Media Komputindo

[6]. Mulyani, Sri. 2017. Metode Analisis dan Perancangan Sistem. Jakarta : Andi Sistematika

[7]. Munawar. 2018. Analisis Perancangan Sistem Berorientasi Objek dengan UML (Unified Modeling Language). Bandung : Informatika

[8]. Oktafiano, M. Muslihodin. 2016. Analisis dan Perancangan Sistem Informasi Menggunakan Model Terstruktur dan UML. Yogyakarta : Andi

[9]. R. N. Rifka. 2017. Step By Step Lancar Membuat SOP. Jogyakarta : Huta Publisher

[10]. Rosa, A.S dan Shalauhuddin, M. 2016. Rekayasa Perangkat Lunak Terstruktur dan Berorientasi Objek. Bandung : Informatika Bandung

[11]. Saleh, Sushanty. 2016. "Model Sistem Penunjang Keputusan Penentuan Jurusan Bagi Siswa Sma Menggunakan Metode Topsis (Studi Kasus Yadika Natar)". Jurnal Informatika, Vol.16, No. 02

[12]. Sitoros, Lamhot. 2015. Algoritma dan Pemograman. Yogyakarta : Andi

[13]. Sitompul, Maria Genia. 2018. Perancangan Sistem Pendukung Keputusan Pemilihan Jurusan Di Sma Berdasarkan Nilai Akademik Dan Minat 